\title{
Speed Control of Grid-Connected Switched Reluctance Generator Driven by Variable Speed Wind Turbine Using Adaptive Neural Network Controller
}

\author{
Hany M. Hasanien ${ }^{1}$, and S. M. Muyeen ${ }^{2}$ \\ ${ }^{1}$ Department of Electrical Power and Machines, Faculty of Eng., Ain shams Univ., Cairo, \\ Egypt \\ ${ }^{2}$ Department of Electrical Engineering, The Petroleum Institute, Abu Dhabi, United Arab \\ Emirates
}

Hanyhasanien@ieee.org

Abstract-In wind energy conversion system, variable speed operation is becoming popular nowadays, where conventional synchronous generators, permanent magnet synchronous generators, and doubly fed induction generators are commercially used as wind generators. Along with the existing and classical solutions of the aforementioned machines used in wind power applications, the switched reluctance generator (SRG) can also be considered as a wind generator due to its inherent characteristics such as simple construction, robustness, low manufacturing cost, etc. This paper presents a novel speed control of switched reluctance generator (SRG) by using adaptive neural network (ANN) controller. The SRG is driven by variable speed wind turbine and it is connected to the grid through an asymmetric half bridge converter, DC-link, and DC-AC inverter system. Speed control is very important for variable speed operation of SRG to ensure maximum power delivery to the grid for any particular wind speed. Detailed modeling and control strategies of SRG as well as other individual components including wind turbine, converter, and inverter systems are presented. The effectiveness of the proposed system is verified with simulation results using the real wind speed data measured at Hokkaido Island, Japan. The dynamic simulation study is carried out using PSCAD/EMTDC.

Index Terms-adaptive neural network, variable speed wind turbine, switched reluctance generator, asymmetric half bridge converter. 


\section{Introduction}

WIND energy has become one of the leading energy sources in renewable power generation at the end of 2007. In 2007, 20,000 MW wind power was installed all over the world. Therefore, the world-wide installed capacity was increased to $94,112 \mathrm{MW}$. This is an increase of $31 \%$ compared with the 2006 market, and represents an overall increase in the global installed capacity around $27 \%[1]$.

The fixed speed wind turbine generator system (WTGS) based on the induction generator as a wind generator is simple and relatively economical technology in the wind power industry [2-4]. Variable speed wind turbine generator system has recently becoming more popular than that of the fixed speed. In 2004, the worldwide market share of variable speed WTGS was more than 60\% [5].

At the present, doubly fed induction generator (DFIG), wound field synchronous generator (WFSG), and permanent magnet synchronous generator (PMSG) are commonly used as variable speed wind generators. Besides those aforementioned classical generators used in variable speed operation of WTGS, the switched reluctance generator (SRG) is considered as a wind generator due to some of its superior characteristics. The SRG is a doubly salient, singly-excited generator. It has unequal number of salient poles on both the rotor and the stator. Only one member (usually the stator) carries the windings, and each two diametrically poles usually form one phase. The rotor has no windings, magnets, or cage windings. It is built up from a stack of salient-pole laminations. The SRG possesses many inherent advantages such as simplicity, robustness, low manufacturing cost, high speed, and high efficiency [6-10]. It is also possible to operate the SRG in variable speed mode. To date, these applications include sourcing aerospace power systems [11], automotive applications [12-13], hybrid 
vehicles [14], and wind turbine applications [15-19]. The aerospace and automotive applications are generally characterized by high speed operation. The wind energy application is characterized by low speed, and high torque operation. In [15], the advantage of the SRG for wind energy application is well reported, though the control strategy is unfocused. The one-phase reluctance generator is proposed for wind energy conversion in [16]. In [17], the grid interfacing of wind energy conversion system is not considered. The authors reported the extension of [17] into [18]. They took into consideration the grid interfacing and used buck converter based topologies for the SRG side control. In a recent work [19], sensorless control of SRG is focused though the overall control strategy of SRGWTGS is not presented.

In this paper, a novel speed control of the switched reluctance generator by using adaptive neural network (ANN) controller is presented. The SRG is driven by variable speed wind turbine and it is connected to the grid through an asymmetric half bridge converter, DC-link, and DC-AC inverter system. Speed control is very important for variable speed operation of SRG to ensure maximum power delivery to the grid for any particular wind speed. Detailed modeling and control strategies of SRG as well as other individual components including wind turbine, converter, and inverter systems are presented. The effectiveness of the proposed system is verified with simulation results using the real wind speed data measured at Hokkaido Island, Japan. The dynamic simulation study is carried out using PSCAD/EMTDC.

For supplying power to the SRG, a voltage source topology is preferred and adopted in this study. It gives well defined voltages over semiconductors and SRG-phases. The premise of a voltage source topology implies a unipolar DC-link voltage with a relatively large DC-link capacitor as energy buffer. The 
asymmetric half bridge converter based on hysteresis control is considered herein for the SRG side control. The ANN controller is considered to control the switching on angle of SRG to run the generator at optimum speed of variable speed wind turbine. The adoption of ANN controller for controlling the SRG speed in this system represents the main contribution in this study. For the grid side interfacing of VSWT-SRG, the space vector pulse width modulation (SVPWM) based inverter system is considered in this study. The sinusoidal PWM is a matured technology, which has been extensively used because it improves the

voltage harmonic components to higher frequencies [20-23]. However, the SVPWM technique has been rigorously used in the last decade, because it allows reducing the commutation loss, and the harmonic current of output voltage. Further, high amplitude modulation indexes are obtained comparable with the conventional sinusoidal PWM technique [22-24]. Therefore, SVPWM is used in this study to generate the switching signals for gate drives of inverter system. The well-known cascaded controller is considered to generate the reference signals for the grid side inverter.

\section{Wind Turbine Modeling}

The mathematical relation for the mechanical power extraction from the wind can be expressed as follows [25]:

$$
P_{M}=0.5 \rho C_{p}(\lambda, \beta) \pi R^{2} V_{W}^{3}[W]
$$

where $P_{M}$ is the extracted power from the wind, $\rho$ is the air density $\left[\mathrm{kg} / \mathrm{m}^{3}\right], \mathrm{R}$ is the blade radius $[\mathrm{m}], \mathrm{V}_{\mathrm{w}}$ is the wind speed $[\mathrm{m} / \mathrm{s}]$, and $\mathrm{C}_{\mathrm{p}}$ is the power coefficient which is a function of both tip speed ratio, $\lambda$, and blade pitch angle, $\beta$ [deg]. $C_{p}$ is expressed by the following equations [26]. 


$$
\begin{aligned}
& C_{p}(\lambda, \beta)=0.5\left(\Gamma-0.02 \beta^{2}-5.6\right) e^{-0.17 \Gamma} \\
& \lambda=\frac{\omega_{m} R}{V_{W}}, \quad \Gamma=\frac{R}{\lambda} \cdot \frac{3600}{1609}
\end{aligned}
$$

where $\omega_{\mathrm{m}}$ is the rotational speed $[\mathrm{rad} / \mathrm{s}]$.

In variable speed WTGS, generated active power depends on the power coefficient, $\mathrm{C}_{\mathrm{p}}$, which is related to the proportion of power extracted from the wind. The optimum values of tip speed ratio and power coefficient are chosen constant values based on the turbine characteristics. For each instantaneous wind speed of VSWT, there is a specific turbine rotational speed, $\omega_{\mathrm{r}}$, which corresponds to the maximum active power, $\mathrm{P}_{\max }$, from the wind generator. In this study, power coefficient curve with maximum power point tracking (MPPT) line is shown in Fig. 1. Since the precise measurement of the wind speed is difficult, it is better to calculate the maximum power, $\mathrm{P}_{\max }$, without the measurement of wind speed by the following formula:

$$
\mathrm{P}_{\max }=0.5 \rho \pi \mathrm{R}^{2}\left(\frac{\omega_{\mathrm{r}} \mathrm{R}}{\lambda_{\text {opt }}}\right)^{3} \mathrm{C}_{\mathrm{p} \_ \text {opt }}
$$

From eq.(4), it is clear that the maximum generated power is proportional to the cube of rotational speed [27-28]. The pitch converter works when the rotor speed exceeds the rated speed to control the mechanical torque of wind turbine [3].

\section{SRG Modeling Including The Converter}

The SRG shown in Fig. 2 is considered as a machine with simple and robust construction as explained in the introduction section [6-10]. Fig. 3 illustrates a three phase SRG converter system. It consists of two controllable power semiconductor switches and two diodes per phase. This circuit is called an asymmetric half bridge inverter for a 3-ph SRG. When the two power switches are turned on current passes through the phase winding. Further, when the two power 
switches are turned off the excitation energy plus additional generated energy is returned back to the dc link via two diodes. Thus each phase has pulse nature parameters (current, flux-linkage, and torque). The torque is produced by the tendency of the rotor poles to align with the stator poles of the excited windings, and it is independent of the phase current direction.

The switched reluctance generator operates by retarding the fire-angles so that conduction period comes after the aligned position, where the phase inductance is decreasing and $d L / d \theta$ is negative. In such case, the energy returned to the $d c$-link during the de-fluxing period $\mathrm{P}_{\mathrm{o}}$ exceeds the excitation energy supplied during the dwell period $\mathrm{P}_{\mathrm{exc}}$ and the difference is provided by the prime mover. The electrical output power can be written as follows:

$$
\mathrm{P}_{\text {out }}=\mathrm{P}_{\mathrm{o}^{-}} \mathrm{P}_{\mathrm{exc}}
$$

The model of SRG for dynamic analysis is composed of the set of phase circuit and mechanical differential equations. In integrating these equations, the problem centers on handling the data (flux-linkage/rotor angle/current) used to describe the magnetic nature of the switched reluctance generator. Different methods have been used for numerical integration of the nonlinear differential equations of the SRG with the magnetization data in the form of a look-up table. In this work, the magnetization curves of the SRG are derived from the measured data. The cubic spline interpolation technique is used. In general, it is more accurate than other standard techniques and gives more smoothed representation of the magnetization curves. The magnetization characteristics are extended using the cubic spline interpolation algorithm to cover the interval of rotor angles between the unaligned and the aligned positions as shown in Fig. 4. The coenergy curves are calculated from the following equation by applying the trapezoidal rule in numerical integration [29]: 


$$
W^{\prime}(\theta, i)=\left.\int_{0}^{i} \psi(\theta, i) d i\right|_{\theta=\text { constan } t}
$$

The static torque curves of the SRG are computed by numerical differentiation of the co-energy using the following equation:

$$
T(\theta, i)=\left.\frac{\partial W^{\prime}(\theta, i)}{\partial \theta}\right|_{i=c o n s t a n t}
$$

The previous characteristics data are carried out using MATLAB toolboxes [30]. These characteristics are stored in the form of look-up tables and used in the laboratory standard power system simulator PSCAD/EMTDC. Thus there are two look-up tables. The first look-up table represents the flux-linkage current curves. The second look-up table includes the static torque characteristics. These tables are available to be used during the computation of the generator differential equations.

To predict the generator performance, it is necessary to solve the differential equations for the appropriate switched conditions and an additional mechanical equation for a variable speed. It is valuable to note that the electromagnetic nature of the generator is reflected in the variation of the phase winding inductance with the rotor displacement, where the mutual inductances with other phase windings are often very small and can be neglected.

The phase equation of the generator has the general following formula:

$$
\frac{\mathrm{d} \Psi_{k}\left(\theta_{\mathrm{k}}, \mathrm{i}_{\mathrm{k}}\right)}{\mathrm{dt}}= \pm \mathrm{V}-\mathrm{R} \mathrm{i}_{\mathrm{K}}
$$

where $\mathrm{R}$ is the phase winding resistance, $\Psi_{\mathrm{k}}$ is the $\mathrm{k}^{\text {th }}$ flux-linkage as a function of the phase current $\mathrm{i}_{\mathrm{k}}$ and the rotor angle $\theta_{\mathrm{k}}$, and $\mathrm{V}$ is the applied voltage. The applied voltage is positive during the conduction period which is the difference between the switching off angle $\theta_{\text {off }}$ and the switching on angle $\theta_{\text {on }}$. Further, $\mathrm{V}$ is 
negative from the switching off angle until the extinction angle $\theta_{\text {ext }}$ which represents the angle corresponding to zero phase current. In other cases $\mathrm{V}$ equals zero.

The generator under study is a three phase, 6/4 SRG, and the rated power is 48 $\mathrm{kw}$ at $3000 \mathrm{rpm}$. The phase resistance is $0.05 \Omega$, the machine inertia is $0.05 \mathrm{kgm}^{2}$, the supply voltage is $240 \mathrm{~V}$ and all the parameters are illustrated in Appendix.

Figs. 5-7 show the flux-linkage, the current, and torque curves of the SRG under normal operating conditions, switching on angle $\theta_{\mathrm{on}}=10^{\circ}$, switching off angle $\theta_{\text {off }}=30^{\circ}$, and speed of $1500 \mathrm{rpm}$. It can be predicted that the switching on angle $\theta_{\text {on }}$ must be after the aligned position (i.e $0^{\circ}$ ) so that conduction period comes after the aligned position, where $d L / d \theta$ is negative.

The control block diagram for generating the gate pulse signals of asymmetric half bridge inverter is shown in Fig. 8. The reference signal is determined from maximum power point tracking (MPPT) algorithm as explained in Sect. II. The conduction signals are generated according to the logic explained above. The SRG rotor angular position, $\theta_{\mathrm{r}}$, is shifted by 30 degree in each phase of three phase $6 / 4$ SRG. The hysteresis controller works well to generate the optimal firing angles for the inverter in order to maximize the output power of the generator according to the reference signal. The optimum rotor speed is maintained by using an adaptive neural network (ANN) controller as explained in the following section, where switching on angle, $\theta_{\text {on }}$ is being controlled.

\section{The adaptive neural network (ANN) controller}

In many classical control systems, some information of the system under study is required in the form of group of algebraic and differential equations. These 
equations express the relation between the inputs and outputs of the system. However, these mathematical models are not easy to develop especially for complex system. They may contain parameters which are difficult to measure, or may change during the system operation. Classical control theory also suffers from some limitations due to the assumptions made in designing the control systems such as linearity, time-invariance, etc. These problems can be overcome by using artificial intelligence (AI) based control techniques. These AI techniques can be used even when the mathematical model of the system is not known.

Essentially, the conventional proportional-integral (PI) and proportionalintegral-derivative (PID) controllers have been utilized in many control applications due to the robustness of these controllers and they offer a wide stability margin. However, the conventional PI and PID controllers are very sensitive to parameter variations and nonlinearity of the dynamic systems. Setting of the parameters of the PI controllers used in cascaded control is cumbersome, especially in power system application which is difficult to express by a mathematical model or transfer function. These problems can be overcome by using artificial intelligence based control techniques. Such control systems can also be less sensitive to parameter variation than classical control systems [31].

In recent years, fuzzy logic control and artificial neural networks techniques have been applied to the control of nonlinear dynamic systems. Unlike classical control strategies, fuzzy logic incorporates an alternative way of thinking, but based on the experience of the designer in tuning the membership functions [32]. The main advantages of the ANN controllers are as follow:

․ Their design does not require the mathematical model of the plant.

- They can lead to improve performance, when properly tuned.

ㄴ They may require less tuning effort than conventional controllers [31]. 
Though the ANN controllers can handle the characteristics of nonlinearity but it may suffer from the convergence time and the long of the training process.

Therefore, in this study, the adaptive ANN controller is presented. The proposed controller ensures fast and accurate dynamic response with an excellent steady state performance.

\section{A) Description of ANN}

ANN controllers are models of computation based on an analogy with biological neural networks. Biological neural networks can learn from experience and it follows that many ANN models can learn, also. Usually, an ANN consists of a highly parallel ensemble of simple computing elements, or neurons. Further, neurons usually have many interconnections with other neurons in the ANN. One class of ANN interconnection strategies is the feedforward strategy. The class of feedforward ANN structure is used in our study. Relevant ANN model design considerations are the selection of inputs, the number of hidden layers, the number of neurons in each hidden layer and tuning the weights of ANN.

The input vector of the ANN controller consists of the reference generator speed

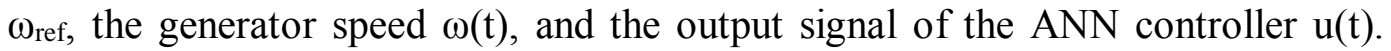
The output of the ANN is added to the inputs as a stabilizing signal. The inputs of the ANN controller have to be carefully chosen, as this dictates the boundedness and stability of the desired trajectories. The selection of number of hidden layers, and the number of neurons in each hidden layer was performed by trial and error, which is the most commonly used method in ANN architecture design. A three layer feedforward neural structure with four neurons in one hidden layer is found to be a good balance between estimation error and ANN complexity. The ANN structure with $3 \times 4 \times 1$ (three neurons in input layer, four neurons in hidden layer, and one neuron in output layer) is shown in Fig. 9. The input nodes were selected 
as equal to the number of input signals and the output nodes as equal to the number of output signals.

The output of a single neuron can be represented by the following equation:

$$
a_{i}=f_{i}\left(\sum_{j=1}^{n} w_{i j} x_{j}(t)+b_{i}\right)
$$

where, $f_{i}$ is the activation function, $w_{i j}$ is the weighting factor, $x_{j}$ is the input signal, and $b_{i}$ is the bias. The most commonly used activation functions are non-linear, continuously varying types between two asymptotic values -1 and +1 . They are called tansigmoid function. The activation function used is the tansigmoid function in both hidden and output layers.

\section{B) Learning Algorithm}

The adaptive ANN controller is based on the Widrow-Hoff adaptation algorithm. The Widrow-Hoff delta rule can be used to adapt the adaline's weight vector [33]. The weight update equation for the original form of the algorithm can be written as:

$$
W(t+1)=W(t)+\alpha \frac{e_{\omega}(t) \cdot x(t)}{|x(t)|^{2}}
$$

where $W(t+1)$ is the next value of the weight vector, $W(t)$ is the present value of the weight vector, and $x(t)$ is the present input vector. The present speed error $\mathrm{e}_{\omega}(\mathrm{t})$ is defined to be the difference between the reference generator speed $\omega_{\text {ref, }}$, and the generator speed $\omega(\mathrm{t})$.

Changing the weights yields a corresponding change in the error:

$$
\Delta e_{\omega}(t)=\Delta\left(\omega_{r e f}-\omega(t)\right)=-x^{T}(t) \Delta W(t)
$$

In accordance with the Widrow-Hoff $\mathrm{dn} b$ elta rule of eq. (10), the weight change is as follows:

$$
\Delta W(t)=W(t+1)-W(t)=\alpha \frac{e_{\omega}(t) \cdot x(t)}{|x(t)|^{2}}
$$


Combining Equations (11) and (12), we obtain

$$
\Delta e_{\omega}(t)=-\alpha \frac{e_{\omega}(t) \cdot x^{T}(t) \cdot x(t)}{|x(t)|^{2}}=-\alpha \cdot e_{\omega}(t)
$$

Therefore, the error is reduced by a factor of $\alpha$ as the weights are changed while holding the input pattern fixed. Presenting a new input pattern starts the next adaptation cycle. The next error is then reduced by a factor of $\alpha$, and the process continues. The initial weight vector is usually chosen to be zero and is adapted until convergence. The choice of $\alpha$ controls stability and speed of convergence. The speed error converges if and only if $0<\alpha<2$. Making $\alpha$ greater than 1 generally does not make sense, since the error would be overcorrected. The total error correction comes with $\alpha=1$. The practical range for $\alpha$ is usually between 0.1 and 1.

This Widrow-Hoff adaptation algorithm is self-normalizing in the sense that the choice of $\alpha$ does not depend on the magnitude of the signals. The weight update is collinear with the input pattern and of a magnitude inversely proportional to $|x(t)|^{2}$. The desired error correction is achieved with a weight change of the smallest possible magnitude.

The Widrow-Hoff adaptation algorithm is used to adapt both all the weighting factors between the input and hidden layers and all the weighting factors between the hidden and output layers. Therefore, the ANN controller in our study is fully adaptive controller.

The output signal of the ANN controller $\mathrm{u}(\mathrm{t})$ after being rescaled is used to modulate the generator phase switching on angle. The advanced switching on angle $\theta_{\text {onnew }}$ can be written as follows [34]:

$$
\theta_{\text {onnew }}=\theta_{\text {oninitial }}-k . u
$$


where, $\theta_{\text {oninitial }}$ is the initial switching on angle $\left(10^{\circ}\right)$, and $k$ is a constant.

Thus, The proposed algorithm corrects error and it minimizes the mean square error between the reference generator speed $\omega_{\text {ref, }}$ and the generator speed $\omega(t)$ over all times. The algorithm is best known with this property.

\section{Control of Grid Side Inverter}

According to the space vector theory, the power electronic converter can operate only eight distinct topologies. Six out of these eight topologies produce a nonzero output voltage. They are known active vectors. The remaining two topologies produce zero output voltage. They are known as zero vectors. The six active vectors are forming a regular hexagon and six sectors in a stationary reference frame. Since the zero vectors have zero magnitude and phase angle, the positions of these vectors are at origin. Detailed modeling and implementation of SVPWM in PSCAD/EMTDC is reported in our earlier work [35]. The grid side inverter controller generates the reference signals and using SVPWM scheme switching signals are generated for the IGBT gate drives used in the inverter.

Control block for the grid side inverter is shown in Fig. 10, which is developed based on the cascaded control scheme. The dq quantities and threephase electrical quantities are related to each other by reference frame transformation. The angle of the transformation is detected from the three phase voltages $\left(\mathrm{v}_{\mathrm{a}}, \mathrm{v}_{\mathrm{b}}, \mathrm{v}_{\mathrm{c}}\right)$ at the high voltage side of the grid side transformer. The DClink voltage can be controlled by the d-axis current. On the other hand, the reactive power of grid-side inverter can be controlled by the q-axis current. The reactive power reference is set in such a way that the terminal voltage at high voltage side of the transformer remains constant. The rated DC-link voltage is $0.24 \mathrm{kV}$. 


\section{Model System}

The model system used for the dynamic analysis of VSWT-SRG is shown in Fig. 11. Here one SRG is connected to an infinite bus through the asymmetric half bridge converter, DC-link capacitor, grid side inverter, transformer, and double circuit transmission line. The system base is $48 \mathrm{kVA}$.

\section{Simulation Results}

Simulation results have been done by using PSCAD/EMTDC [36]. Dynamic characteristic of VSWT-SRG is analyzed under wide range of wind speed variation shown in Fig. 12. This wind speed characteristic is a real data measured in Hokkaido Island of Japan. The control objective is certainly to maximize the wind power capture by adjusting rotor speed of the SRG according to the wind speed variation, provided that the captured power should not exceed the rated power of SRG. The chopped current control mode is carried out for the SRG in order to protect the asymmetric half bridge inverter from high currents. Fig. 13 shows the rotor speed of SRG and optimum rotor speed calculated from MPPT. It can be noted that the two speed responses are closed to each other. This means that the SRG is closely running at optimal speed for MPPT using the proposed ANN controller. The responses of real and reactive power at the grid side inverter are shown in Figs. 14 and 15, respectively. The terminal voltage at the grid side is maintained constant as shown in Fig. 16. The response of DC-link voltage is shown in Fig. 17. The output response from the adaptive neural network is shown in Fig. 18. This signal is used to generate the switching on angle $\theta_{\text {on. }}$ From the simulation results, it can be seen that the proposed control system is well suitable for wind power application. 


\section{Conclusions}

In this paper, a novel application of adaptive neural network controller has presented for controlling the speed of switched reluctance generator driven by variable speed wind turbine. The switched reluctance generator is connected to the grid through an asymmetric half bridge converter, DC-link, and DC-AC inverter system. The detailed modeling and control strategies for the whole system under study have been presented. The proposed control strategy helps the wind generator to provide maximum power to the grid and also supply or absorb necessary reactive power to maintain constant terminal voltage of the grid as required by transmission system operators (TSOs). The switching on angle of SRG has controlled by the adaptive neural network controller and thus, excellent dynamic performance is achieved. This feature is a new incorporation in the field of variable speed wind power generation system where rotor speed of SRG is needed to control precisely to extract maximum power from the wind. Finally, it has been concluded that the proposed control system is well suitable with variable speed wind turbine driving a switched reluctance generator.

The proposed system is planned to verify in real time environment using ACE 1103 dSPACE system and Matlab/Simulink, which will be reported in future.

\section{References}

[1] The Global Wind Energy Council, GWEC Latest News, 2008, “US, China \& Spain lead world wind power market in 2007," February, 2008, [Online], http://www.gwec.net/

[2] Vladislav Akhmatov, "Induction Generators for Wind Power," Multi Science Pub Co Ltd, ISBN 9780906522400, August 2007.

[3] S. M. Muyeen, J. Tamura, and T. Murata, "Stability Augmentation of a Grid-connected Wind Farm,” Springer-Verlag London, ISBN 978-1-84800-315-6, October 2008. 
[4] Daniel J.Trudnowski et al., "Fixed-speed wind-generator and wind-park modeling for transient stability studies," IEEE Trans. on Power Systems, vol.19, no.4, pp.1911-1917, 2004.

[5] F. V. hulle, "Large Scale Integration of Wind Energy in the European Power Supply Analysis, Issue and Recommendations,” EWEA, Tech. Rep., December 2005.

[6] T. J. E. Miller,"Switched reluctance motors and their control”, Oxford University Press, 1993.

[7] P. J. Lawrenson, "Variable speed switched reluctance motors", IEE Proc. vol. 127, no. 4, pp. 253-265, 1980.

[8] Hany.M. Hasanien, N.H. Saad, M.A. Mostfa, and M.A. Badr, "Speed control of axial laminations switched reluctance motor provided with digital pole placement controller", in Proc. of the international conference on electrical machines (ICEM), Sept. 2006.

[9] Hany M. Hasanien, S. M. Muyeen, and J. Tamura, "Switched Reluctance Machine", Praise Worthy Prize, Italy, ISBN 978-88-96329-02-3, Feb. 2010.

[10]D. Torrey, " Switched reluctance generators and their control ", IEEE Trans. on Ind. Electron., vol. 49, no. 1, pp. 3-13, Feb. 2002.

[11]D. E. Cameron and J. H. Lang, "The control of high-speed variable reluctance generators in electric power systems," IEEE Trans. Ind. Appl., vol. 29, no. 6, pp. 1106-1109, Nov./Dec. 1993.

[12] M. Besbes, M. Gasbi, E. Hoang, M. Lecrivian, B. Grioni, and C. Plasse, SRM design for starter-alternator system," in Proc. Int. Conf. Electric Machines, 2000, pp. 1931-1935.

[13] C. Ferreira, S. R. Jones, W. Heglund, and W. D. Jones, "Detailed design of a 30-kw switched reluctance starter/generator system for a gas turbine engine applications," IEEE Trans. Ind. Appl., vol. 31, no. 3, pp. 553-561, May/Jun. 1995.

[14] J. M. Kokernak, D. A. Torrey and M. Kaplan, “A switched reluctance starter/ alternator for hybrid electric vehicles”, Power Electronics Proc ( PCIM) Conference, pp. 74-80, 1999.

[15]D. A. Torrey, "Variable reluctance generators in wind-energy systems," in Proc. IEEE Power Electronics Specialists Conf., 1993, pp. 561-567.

[16]L. Ribickis, E. Kamolins, N. Levin, and V. Pugachev, "One-Phase Reluctance Generators in Low-Power Wind Plants," 12th European Conference on Power Electronics and Applications (EPE2007), September 2007. 
[17] R. Cardenas,W. F. Ray, and G.M. Asher, "Switched reluctance generators for wind energy applications," in Proc. IEEE Power Electronics Specialists Conf. (PESC95), 1995, pp. 559564.

[18] Roberto Cardenas, Ruben Pena, Marcelo Perez, Jon Clare, Greg Asher, and Patrick Wheeler, "Control of a Switched Reluctance Generator for Variable-Speed Wind Energy Applications," IEEE Trans. on Energy Conversion, vol.20, no.4, 2005.

[19]E. Echenique, J. Dixon, R. Cárdenas, and R. Peña, "Sensorless Control for a Switched Reluctance Wind Generator, Based on Current Slopes and Neural Networks," IEEE Trans. on Industrial Electronics, vol.56, no.3, pp.817-825, March 2009.

[20] J. Holtz, "Pulse width Modulation for Electronic Power Conversion," Proc. of the IEEE, Vol. 82, No. 8, pp. 1194-1213, 1994.

[21] D. W. Novotny and T. A. Lipo, Vector Control and Dynamics of AC Drives, SpringerVerlag, New York, 1996.

[22] J.R Rodriguez, J.W Dixon, J.R Espinoza, J. Pontt, P. Lezana, "PWM regenerative rectifiers: state of the art," IEEE Trans. On Industrial Electronics, vol.52, no.1, pp.5-22, 2005.

[23] K. Zhou and D. Wang, "Relationship between Space-Vector Modulation and Three-Phase Carrier-Based PWM: A Comprehensive Analysis," IEEE Trans. On Industrial Electronics, vol.49, no.1, pp.186-196, 2002.

[24] J.I. Leon, S.Vazquez, R. Portillo, L.G. Franquelo, J.M. Carrasco, P.W. Wheeler, A.J. Watson, “Three-Dimensional Feedforward Space Vector Modulation Applied to Multilevel DiodeClamped Converters," IEEE Trans. On Industrial Electronics, vol.56, no.1, pp.101 - 109, Jan. 2009.

[25] S. Heier, Grid Integration of Wind Energy Conversion System, Chicester, UK, John Wiley \& Sons Ltd., 1998.

[26] O.Wasynczuk et.al. , "Dynamic Behavior of a Class of Wind Turbine Generators During Random Wind Fluctuations," IEEE Transactions on Power Apparatus and Systems, vol 1. PAS-100, no. 6, pp.2837-2854, 1981.

[27] M. Z. Dosaev, V. A. Samsonov, and Yu. D. Seliutski, "On the Dynamics of a Small-Scale Wind Power Generator," Doklady Physics, Vol. 52, No. 9, pp. 493-495. , 2007.

[28] M.A. Yurdusev, R. Ata and N.S. Çetin, "Assessment of optimum tip speed ratio in wind turbines using artificial neural networks, Energy, vol. 31, Issue 12, pp. 2153-2161 Sept. 2006. 
[29] Hany M. Hasanien, "Steady state performance of switched reluctance generator", Journal of electrical engineering (JEE), vol. 8, no. 1, pp 53-60. April 2008.

[30] Release 2008a, "MATLAB Toolbox," The Math Works press, March 2008.

[31] Muhammad H Rashid, "Power Electronics Handbook", reference book, Second edition, Elsevier Inc, 2007.

[32] Ahmed Rubaai, Daniel Ricketts, and M. David Kankam, "Development and implementation of an adaptive Fuzzy-Neural-Network controller for brushless drives”, IEEE Transactions on Industry Applications, vol. 38, No. 2, March/April 2002, pp. 441-447.

[33]B. Widrow and M. A. Lehr, "30 years of adaptive neural networks: Perceptron, madaline, and backpropagation," in Proc. IEEE, vol. 78, pp. 1415-1442, Sept. 1990.

[34] Hany M. Hasanien, "FPGA implementation of adaptive ANN controller for speed regulation of permanent magnet stepper motor drives," Energy Conversion and Management, vol. 52, issue 2, pp. 1252-1257, Feb. 2011.

[35] S. M. Muyeen, Mohammad Abdul Mannan, Mohd. Hasan Ali, R. Takahashi, T.Murata, and J.Tamura, "Simulation Technique \& Application of Space-Vector PWM Method in PSCAD/EMTDC," CD Record of International Conference on Information \& Communication Technology (ICICT 2007), Reference no. 041, Dhaka, Bangladesh, March 07-09, 2007.

[36] PSCAD/EMTDC Manual, Manitoba HVDC Research Center, 1994.

\section{Appendix}

The switched reluctance generator specifications are illustrated in Table I.

TABLE I

SRG SPECIFICATIONS

\begin{tabular}{|c|c|}
\hline The phase winding resistance & $0.05 \Omega$ \\
\hline The DC supply voltage & $240 \mathrm{~V}$ \\
\hline The maximum phase current & $200 \mathrm{~A}$ \\
\hline The rated torque & 152.79 N.m \\
\hline The rated speed & $3000 \mathrm{rpm}$ \\
\hline The rated power & $48 \mathrm{KW}$ \\
\hline No. of motor phases & 3 \\
\hline The rotor moment of inertia & $0.05 \mathrm{Kg} . \mathrm{m}^{2}$ \\
\hline The friction coefficient & 0.02 N.m.s \\
\hline
\end{tabular}




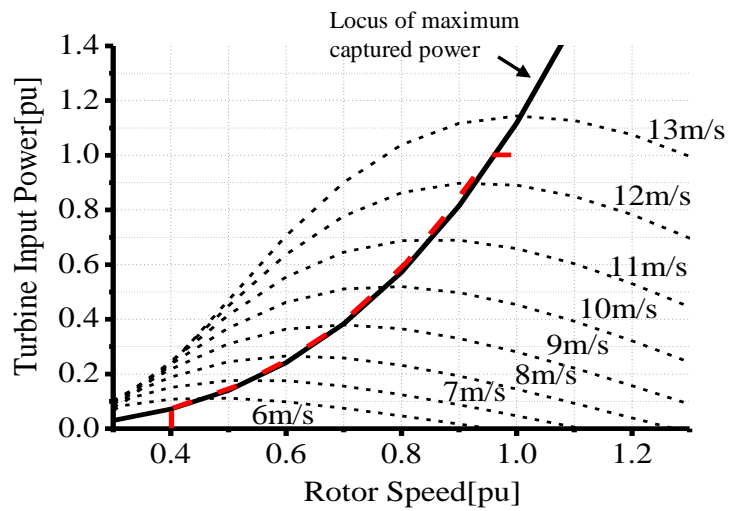

Fig. 1. Wind turbine characteristics for variable speed operation

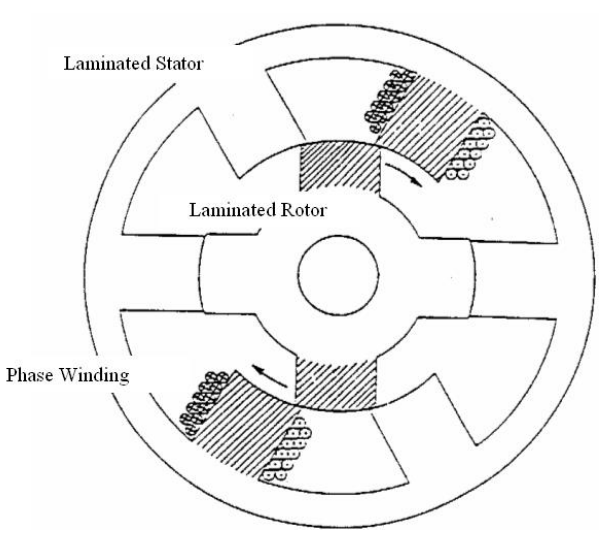

Fig. 2. A cross section of a 3 phase, 6/4 SRG.

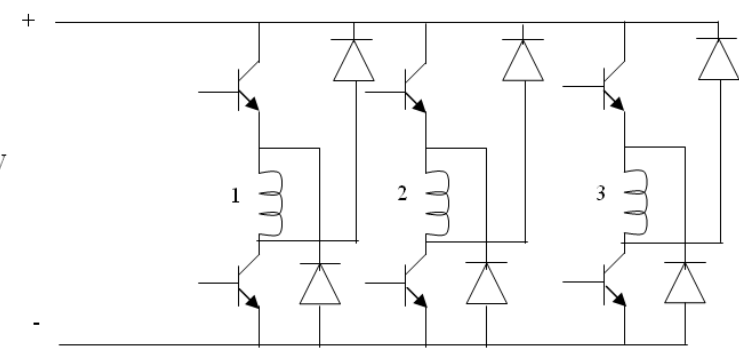

Fig. 3. Asymmetric half bridge inverter of three phase SRG. 


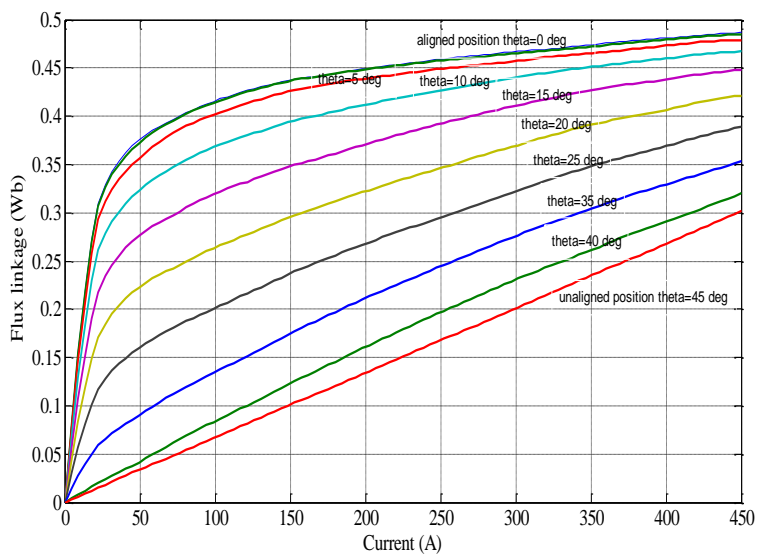

Fig. 4. The phase flux-linkage as a function of current and rotor position

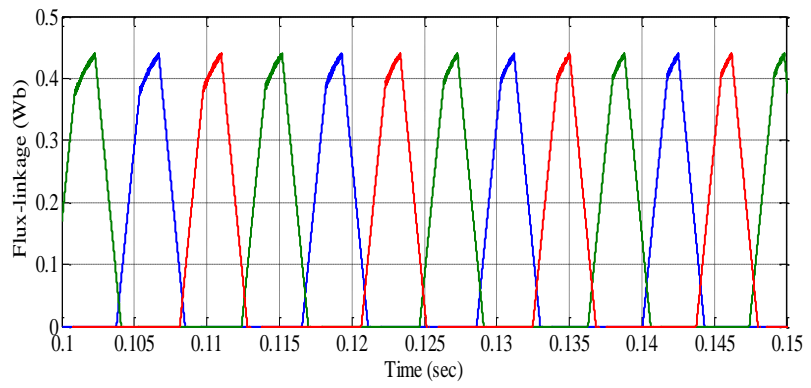

Fig. 5. The flux-linkage response of the SRG under $\theta_{\text {on }}=10^{\circ}$ and $\theta_{\text {off }}=30^{\circ}$.

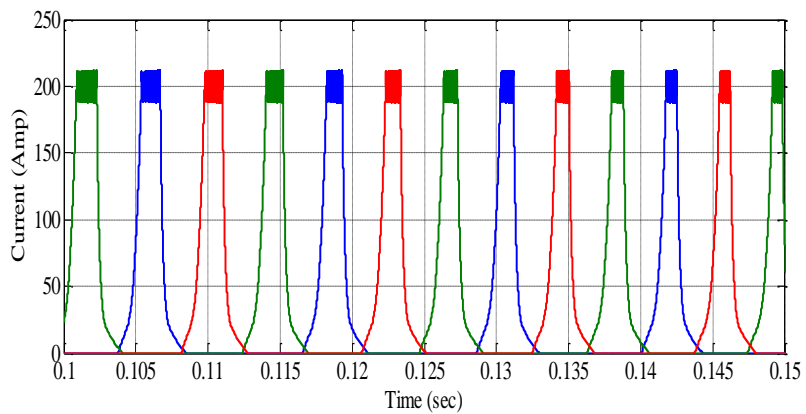

Fig. 6. The current response of the SRG under $\theta_{\text {on }}=10^{\circ}$ and $\theta_{\text {off }}=30^{\circ}$

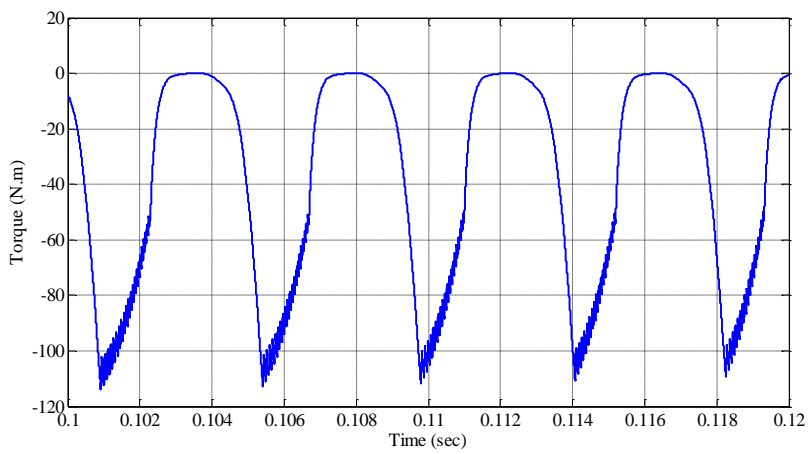

Fig. 7. The torque response of the SRG under $\theta_{\text {on }}=10^{\circ}$ and $\theta_{\text {off }}=30^{\circ}$.

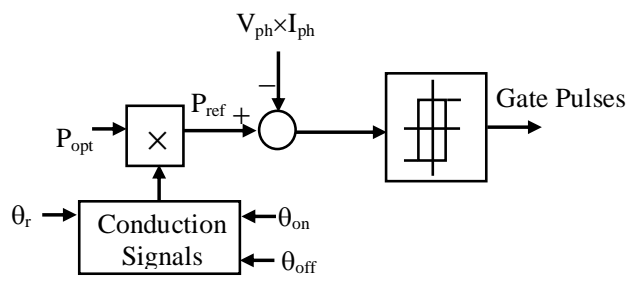




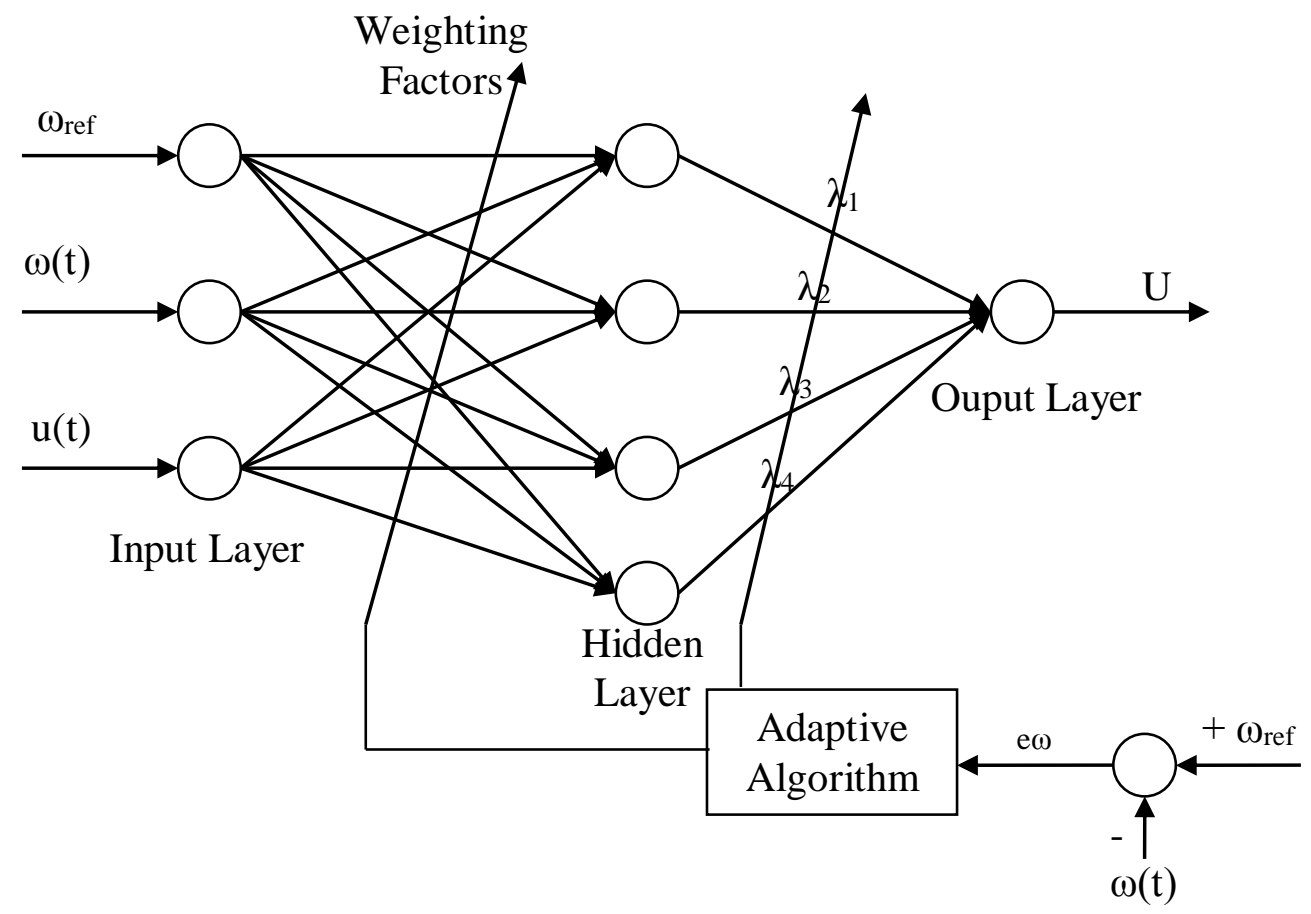

Fig. 9. The adaptive artificial neural network structure.

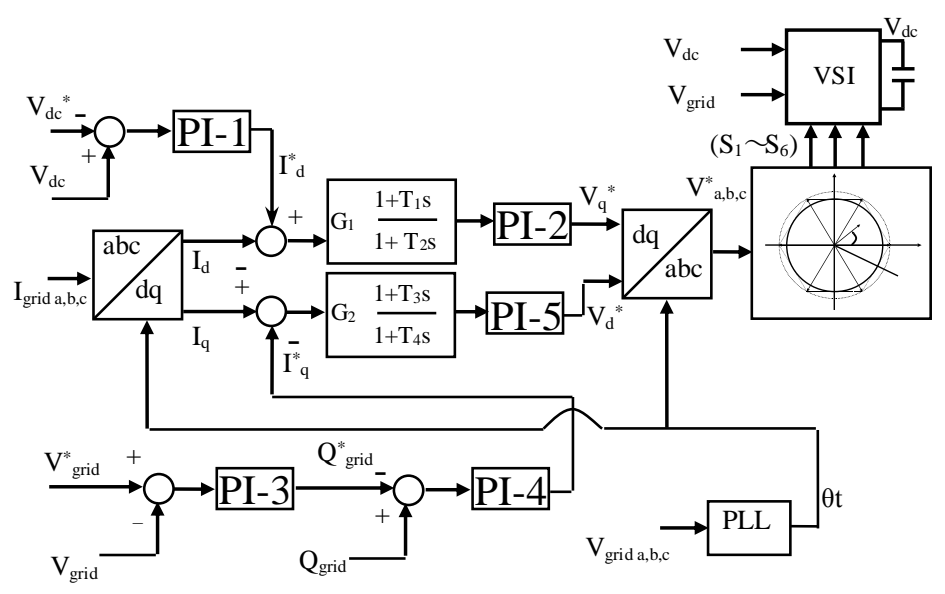

Fig. 10. Control block diagram of grid side inverter

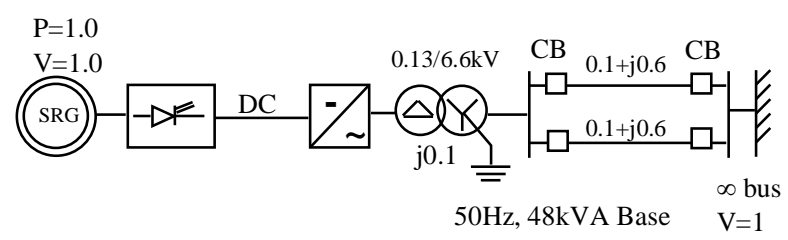

Fig. 11. Model System 


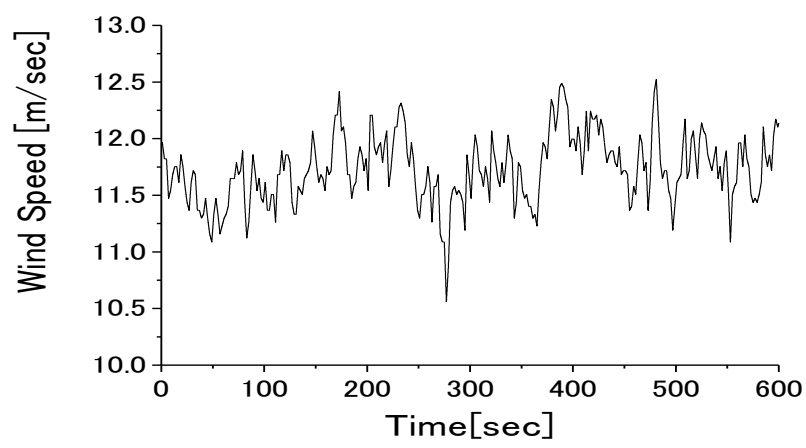

Fig. 12. Wind Speed

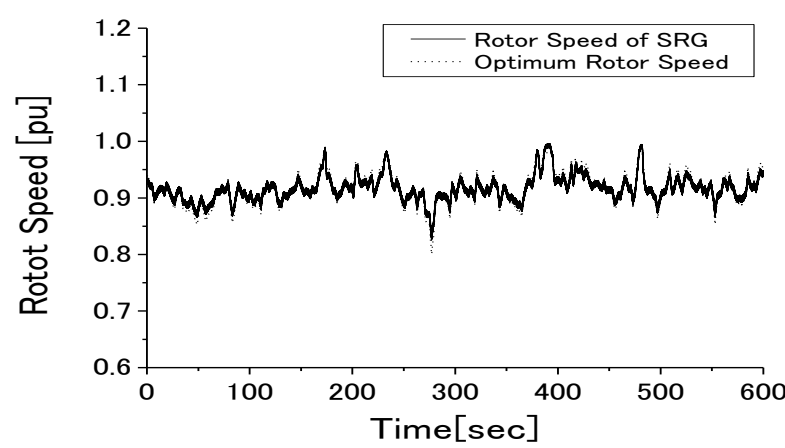

Fig. 13. Rotor speed of SRG

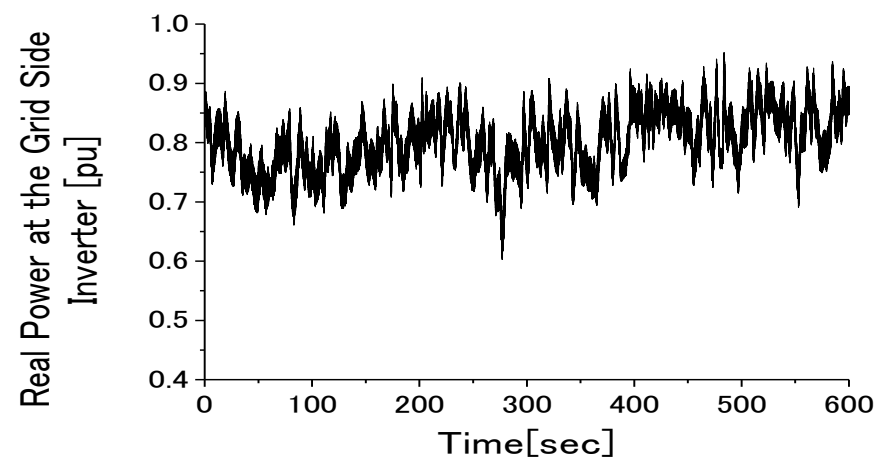

Fig. 14. Real power of grid-side inverter

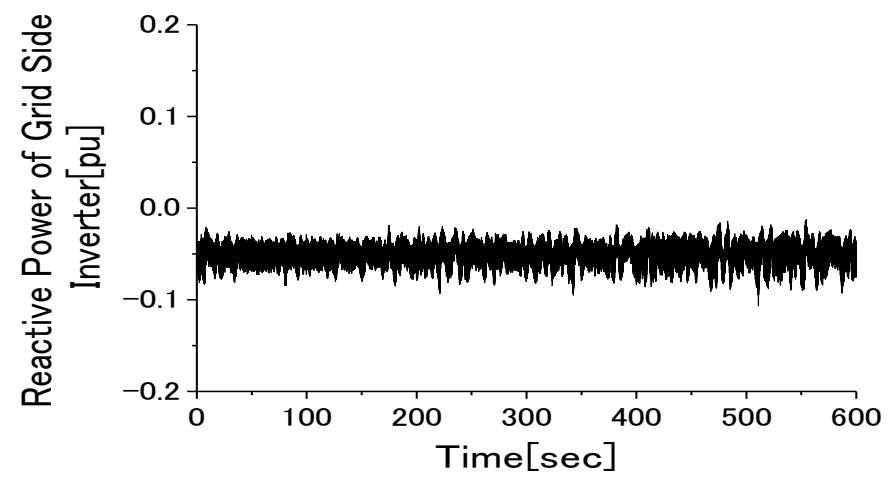


Fig. 15. Reactive power of grid-side inverter

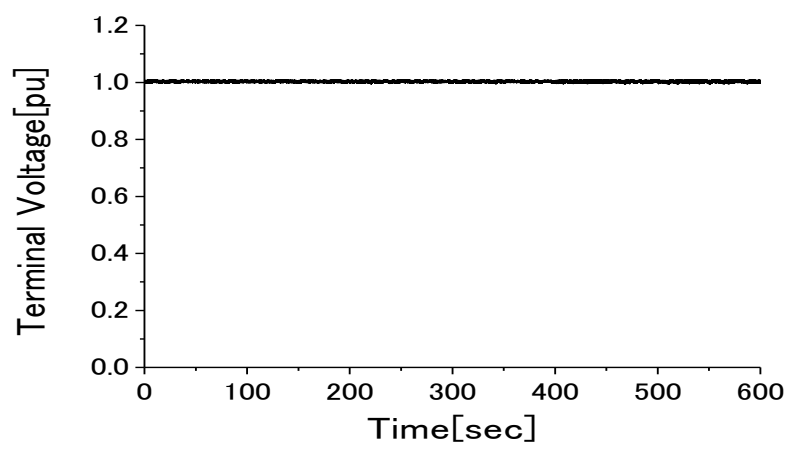

Fig. 16. Terminal voltage of the grid

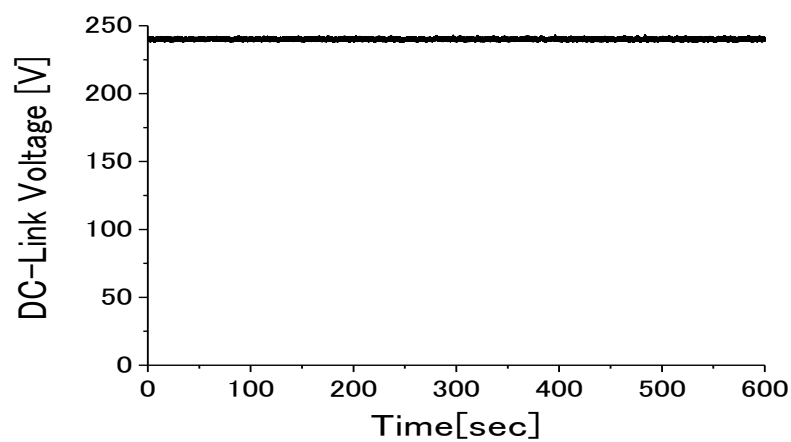

Fig. 17. DC-link circuit voltage

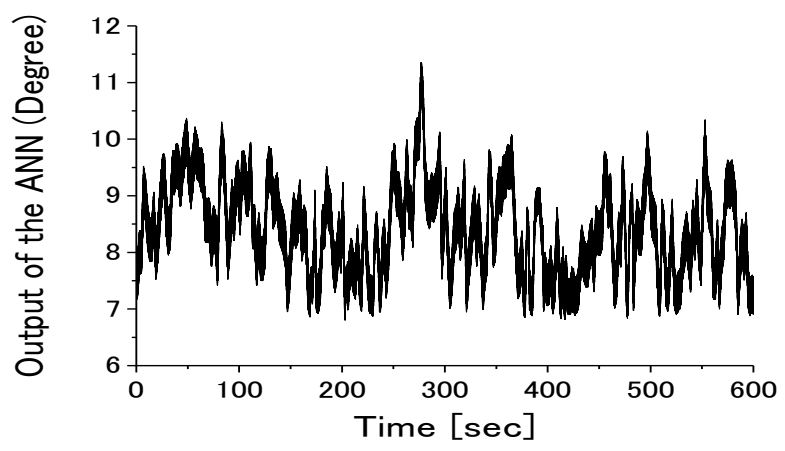

Fig. 18. Output from the adaptive neural network 